\title{
El fenómeno del meme en la estrategia creativa de Netflix España en Twitter
}

\section{The meme phenomenon in the creative strategy of Netflix Spain on Twitter}

\section{0 fenômeno do meme na estratégia criativa da Netflix Espanha no Twitter}

\author{
Isidoro Arroyo-Almaraz \\ Profesor Titular \\ (Universidad Rey Juan Carlos de Madrid) \\ https://orcid.org/0000-0003-4000-5167 \\ España \\ Richard Díaz-Molina \\ Ejecutivo de Cuentas \\ (The Com Agency) \\ https://orcid.org/0000-0002-7453-9549 \\ España
}

Fecha de recepción: 21 de diciembre de 2020

Fecha de revisión: 1 de febrero de 2021

Fecha de aceptación: 15 de mayo de 2021

Fecha de publicación: 1 de julio de 2021

Para citar este artículo: Arroyo-Almaraz , I. y Díaz-Molina, R. (2021). El fenómeno del meme en la estrategia creativa de Netflix España en Twitter, Icono 14, 19(2), 312-338. doi: 10.7195/ri14.v19i2.1660 


\section{Resumen}

El objeto de estudio es conocer el uso creativo que Netflix España hace de los memes para atraer a su audiencia para promocionar sus contenidos en Twitter, elegida por su naturaleza pública, amplia influencia, y creciente capacidad de alcance. El objetivo principal es evaluar si los memes establecen engagement que viralice los contenidos. Los objetivos específicos son: medir el grado de atracción que los memes compartidos generan en comparación con otros recursos publicados por Netflix España en su cuenta de Twitter (@NetflixES), analizar qué formatos y contenidos presentan mayores reenvios, me gusta, y respuestas, e identificar los objetivos de comunicación para los que se emplean los memes. Se usa una metodología mixta cuantitativa y cualitativa con una muestra de 112 memes de 307 publicaciones del cuarto trimestre de 2019. Como resultados: los memes muestran el tercer mayor grado de atracción tras emoticonos y enlace en redes; no hay una correspondencia directa entre los formatos más usados: texto visual, imagen macro y clip de video, y los formatos con mayores niveles de interacción: gráfico, collage, y clip de video. Los memes se publican con el objetivo comunicativo de promocionar la marca Netflix, la oferta del catálogo, y establecer conversaciones con los usuarios. Se concluye que los memes son una forma preferente de comunicación en su estrategia creativa, capaz de establecer una atracción muy poderosa a través de la creación de vínculos emocionales entre la plataforma Netflix y sus usuarios.

Palabras clave: Estrategia creativa; Meme; Netflix; Viralización; Engagement; Twitter

\section{Abstract}

The objective of this study is to determine what creative use Netflix Spain makes of audience-capturing memes to promote its contents on Twitter, chosen for its public nature, broad-ranging influence and growing reach. The main objective is to evaluate whether the memes lead to a level of engagement that makes their contents go viral. The specific objectives are: to measure the level of attraction that shared memes generate compared with other resources published by Netflix Spain on its Twitter account (@NetflixES), to analyse which formats and contents result in the most retweets, likes and replies, and to identify for which communication goals the memes are used. The study uses a mixed quantitative and qualitative methodology, 
with a sample of 112 memes from 307 publications from the fourth quarter of 2019. Findings: memes result in the third-biggest form of attraction after emoticons and weblinks; there is no direct connection between the most frequently used formats (visual text, image macro and video clip) and the most interactive formats (graphic, collage and video clip). Memes are published with the goal of promoting the Netflix brand and its catalogue as well as to generate discussion among users. It is concluded that memes are a preferred form of communication in the creative strategy of Netflix Spain. They are a highly powerful form of attraction that creates emotional ties between the Netflix platform and its users.

Keywords: Creative strategy; Meme; Netflix; Viralization; Engagement; Twitter

\section{Resumo}

Estudou o uso criativo de memes que a plataforma audiovisual Netflix Espanha utiliza para atrair a sua audiência para promover o seu conteúdo no Twitter. Memes são um fenómeno que a Netflix usa amplamente através do Twitter devido à sua natureza pública, ampla influência e alcance crescente. 0 principal objetivo é avaliar se os memes estabelecem engagement que viraliza o conteúdo. 0 objetivo está dividido em: a medição do grau de atração gerado pelos memes compartilhados em comparação com outros recursos publicados pela Netflix Espanha na sua conta no Twitter (@NetflixES); a análise de quais formatos e conteúdos apresentam maior grau de encaminhamento, likes, resposta e identifique os objetivos da comunicação para quem usa memes. É usada uma metodologia mista: quantitativa e qualitative com uma amostra de 112 memes de 307 postagens do quarto trimestre de 2019.. Como resultado: os memes mudam o terceiro maior atrativo dos emoticons e o networking; não há correspondência direta entre os formatos mais utilizados: texto visual, macroimagem e videoclipe e os formatos com maior nivel de interação: gráfico, colagem e videoclipe. Os memes são publicados com o propósito comunicativo de divulgação da marca Netflix, oferta do catálogo e iniciar conversas com usuários. Conclui-se que os memes são uma forma preferencial de comunicação na sua estratégia criativa, capaz de estabelecer uma atração muito poderosa através da criação de laços emocionais entre a plataforma Netflix e os seus usuários.

Palavras chave: Estratégia criativa; Meme; Netflix; Viralização; Comprometimento; Twitter 


\section{Introducción}

Los memes de Internet están adquiriendo una mayor relevancia en la comunicación digital a través de las redes sociales. Los memes son una realidad semiótica y retórica compleja. Según Shifman citado en Ruiz-Martínez (2018, p.996) "éstos están contribuyendo a articular el discurso público, y sirven para conformar y reflejar estados de opinión". Además de utilizarse con un fin meramente lúdico, también contribuyen a la discusión política. Según Ruiz-Martínez (2018) el auge y la popularidad de movimientos como el 15M o Podemos, se explican en parte por la creación y difusión de memes a través de Internet. Los últimos procesos electorales que han surgido en nuestro país han hecho proliferar numerosos memes. En definitiva, y como señala Milner (2012), los memes son una forma de capital cultural y configuran muchas de las características de la comunicación digital. Capital cultural significa, por un lado que, con esta forma de comunicación: materializamos la fuerza con la que queremos trasmitir un discurso, visibilizamos diferentes realidades sociales, adquirimos cierta autoridad y son medio para el debate político; $y$, por otro lado, son compartidos por una gran cantidad de gente, además de ser creados por ellos mismos y reformulados.

Los memes han ido alcanzando popularidad a través de los años, manteniendo una tendencia alcista en sus búsquedas en Google. A través de la aplicación Google Trends se puede ver este ascenso desde el mes de febrero de 2012 hasta marzo de 2020.

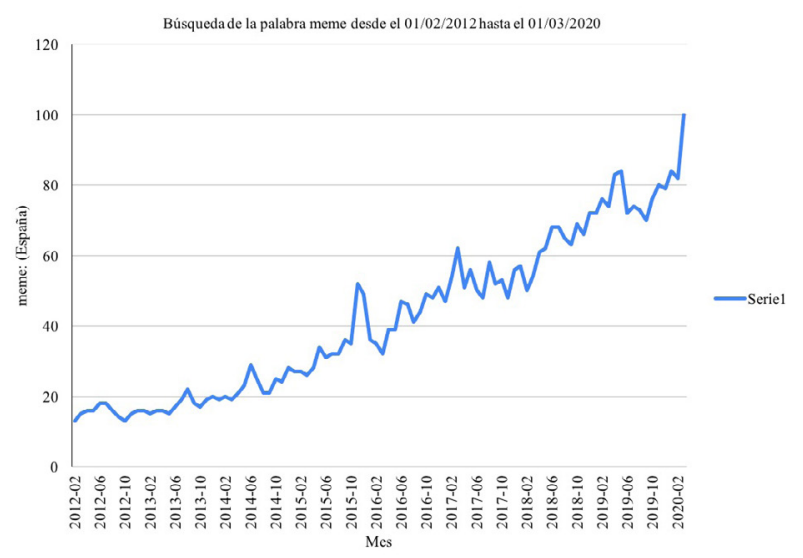

Gráfico 1: Tendencia alcista de la palabra meme desde el año 1/02/2012 hasta 16/03/2020. Fuente: Google Trends. 
Para Chans (2018), los usuarios desean compartirlos debido a sus grandes capacidades para comunicar actitudes, sentimientos y situaciones. Dado que los ciudadanos están invirtiendo cada vez más tiempo en redes sociales, y que este fenómeno se ha convertido en un elemento nativo de su lenguaje, no es de extrañar que Netflix esté interesada en su utilización como reclamo para la audiencia. Según el portal Puro Marketing (2017, 10 de mayo) también las marcas quieren publicar contenidos en redes sociales que no sólo les ayuden a estar ahí, sino que además logren mejorar su conexión con los consumidores y sus vínculos con ellos. Tienen que darle a sus audiencias lo que esperan encontrar en ese escenario.

Por todo ello, el objeto de estudio de esta investigación es conocer cómo la plataforma Netflix utiliza el meme y lo implementa en su estrategia creativa en Twitter.

Otros estudios como el de Martín-Quevedo, Fernández-Gómez y Segado-Boj (2019) ya lo hicieron en la red social Instagram comparando dos mercados el de EE.UU. y el de España en noviembre de 2017 pero, dado que sus resultados mostraron grandes diferencias entre sus cuentas de Instagram en los dos mercados (España y EE. UU.), hemos elegido hacerlo solo para España para poner en discusión nuestros resultados con los encontrados en investigaciones previas sobre contenidos españoles.

\subsection{0rigen del concepto de meme}

Richard Dawkins en 1976 acuñó el término por similitud con gen pero aplicado a la memoria. Un meme sería el equivalente cultural a un gen biológico que explicaría las diferencias con el resto de las especies como hecho diferencial responsable de la evolución (Dawkins, 2004) o, según Torres (2015), como un elemento más.

Los memes se configurarían como una unidad de cultura que tienen la capacidad de transmitirse y sobrevivir en un determinado ecosistema social $\mathrm{y}$, tal y como les ocurre a los genes, sufrir mutaciones y conjugarse con otros memes. Por tanto, según esta teoría, los memes son ideas, modas, religiones, lenguajes, dichos o maneras de pensar, que, al igual que los virus, parecen multiplicarse y propagarse de una mente a otra dentro de nuestra vida cultural. 
Dawkins $(1976,2004)$ establece tres propiedades que subyacen al concepto de meme: la longevidad, capacidad para mantenerse en el tiempo; la fecundidad, capacidad para reproducirse; $\mathrm{y}$, por último, la fidelidad al original en la transmisión, ya que son replicados de una forma alterada y sometida a una mutación constante.

Pérez, Aguilar y Guillermo (2014, p.81) explicando a Dawkins (1976) llegan a la idea de que "los memes son una unidad de sentido, cuya replicación es posible de una forma tanto transversal (en distintos grupos dispersos geográficamente, pero con lazos de comunicación entre ellos y ubicados en tiempos más o menos coincidentes), como longitudinal (a lo largo de varias generaciones en el tiempo)".

Esta replicación se da por factores psicosociales y se manifiesta cuando el meme es utilizado por diversas personas de manera repetida, sumándose a un imaginario común que forma parte de una cultura determinada.

Se pueden diferenciar dos tendencias generales a la hora de estudiar el fenómeno comunicativo del meme: las posturas instrumentales-objetivas y las mentalistas. Por un lado, las mentalistas lo tratan desde una perspectiva intangible, como lo hace el propio Dawkins (1976); y por otro lado, las instrumentales-objetivas lo tratan como un fenómeno observable y tangible, enfatizando las manifestaciones tangibles. Metodológicamente y según Pérez, Aguilar y Guillermo (2014, p.84) los memes en Internet, como unidades culturales, pueden constituirse en un objeto de observación concreto, que puede existir en las mentes de los actores sociales que lo comparten.

\subsection{Delimitación teórica del meme de Internet}

Este concepto primigenio se ha adaptado al nuevo contexto comunicativo y social, convirtiéndose en una herramienta indispensable para los usuarios del mundo online $\mathrm{y}$, sobre todo, de redes sociales. Davidson (2012, p.122) señala el meme de Internet como una pieza cultural, configurada típicamente como una broma o un elemento de carácter humorístico, que adquiere influencia a través de la transmisión digital. Este podría ser una imagen, frase, canción o video. A través de esta frase se encuentran sus cualidades esenciales: es un elemento cultural (que tiene 
una intención de comunicar algo); casi siempre tratado con un tono humorístico; y compartido a través de la red. Su distribución online le otorga unas posibilidades de viralización mayores, siempre y cuando su contenido tenga una correspondencia retórica con la realidad social que desea representar. Según Lankshear y Knobel (2007, p.224), haciendo referencias a estas nuevas formas de alfabetización, aclaran que son formas socialmente reconocidas que generan, comunican y negocian contenidos significativos a través de textos codificados dentro de contextos de participación. Son, por tanto, discursos ideológicos concretos con una visión particular sobre el mundo que ponen en circulación determinados grupos sociales o institucionales. Los referentes son expresados mediante significados compartidos en el interior de dichas comunidades, provocando que los memes tengan un determinado propósito. El éxito, por lo tanto, radicará en hallar las referencias más idóneas en relación con el contexto que se le quiera dar al meme. "Estas alusiones a ciertas subculturas, técnicas y etiquetas crean un equilibrio entre norma o convención y sus posibles desvíos" (Ruiz-Martínez 2018, p.1001). Esta contraposición esencialmente retórica es abordada por el El Groupe $\mu$ (1993) quien califica a la convención como una forma sistemática de alteración que se extiende a la totalidad del mensaje, exigiendo una estructura no sorpresiva, repetida y que hace aumentar la previsibilidad, facilitando a su vez el reconocimiento y la cohesión del meme a la hora de difundirse.

El desvío sería como una alteración localizada y sorprendente con respecto a la norma, lo que hace disminuir su previsibilidad y permite que sigan conservando su carácter impactante, fresco y con utilidad comunicativa para los internautas. Shifman (2014, p.100) habla de diferentes niveles de alfabetización: algunos pueden ser entendidos (y creados) por casi cualquier persona, mientras que otros requieren conocimientos detallados sobre una subcultura de memes, por lo que apropiarse y difundirlos de forma anónima no solo implica imitar o apropiarse y mezclar contenidos, sino también saber compartir los contenidos. El fenómeno meme no se puede analizar al margen de la comunidad usuaria. Es la comunidad usuaria la que tiene capacidad para convertir un contenido en meme y es la que nos puede dar información sobre los contenidos que aportan engagement. Un contenido, por tener un formato concreto imagen macro, por ejemplo, no es susceptible de ser compartido. 


\section{MONOGRÁFICO}

Para que un meme tenga éxito debe ser, según Davidson (2012), comunicable y a la vez fácilmente configurable. La primera característica hace referencia a su calidad espacial: mucha más gente lo comparte; y la segunda lleva implícita una proporcionalidad directa con el tiempo: cuanta más gente se apropie de él, más usos y sentidos se le pueden aplicar, haciendo que el meme perdure y no pase de moda. Esta mutación constante ha hecho que autores como Shifman (2014) lo estudien, no como una unidad aislada, sino como grupos que cumplen unas cualidades comunes. Siendo no solo objetos aislados o cerrados sino también elementos abiertos que van cambiando a través de micro repeticiones y diferencias.

Además, podemos caracterizar a los memes como elementos fuertemente intertextuales que se comunican entre sí a través de su propia replicación. Mediante esta cualidad, el meme se recontextualiza, adquiere nuevos significados y hace que su información sea más diversa. Por este procedimiento, los memes se afianzan en el imaginario colectivo tejiendo a lo largo de ellos una red de referencias que los hace identificables. Estas referencias están muchas veces vinculadas a la cultura popular de masas difundida por el mundo online. El hecho de que sean elementos intertextuales no solo motiva que se reproduzcan a través de ser citados o referenciados sino que, además, el contenido del meme integra la relación de una idea 0 argumento con un elemento de la cultura popular, encuadrado dentro del imaginario que el usuario debe poseer para comprenderlo.

No es fácil iniciarse en la comprensión de los memes, ya que se codifican como un argot complicado para aquellos que se adentran, por primera vez, en el proceso de compartir y crear este tipo de elementos. Una de las estructuras semióticas más repetidas por los memes de Internet es lo que se ha dado a conocer como imágenes macro, que se caracterizan por ser una imagen estática acompañada de un texto. Sin embargo, un contenido no necesariamente será compartido solo por tener un formato concreto. Además, en palabras de Ruiz-Martínez (2018, p.1011): “en ocasiones, este texto suele estar dividido en dos partes: una prótasis o proposición en la parte superior de la imagen, y una apódosis a modo de conclusión, refutación o paradoja en la parte inferior".

Este tipo de estructura reproduce un esquema semiótico común, que es imprescindible para su comprensión: las imágenes precisan una forma estereotipada de 
emoción que suscite risa o con tono humorístico o una imagen que muestra una acción captada en un momento determinado de una persona, animal o cosa, en un contexto gracioso.

Estas imágenes se convierten en contenedores de emociones y connotaciones con una carga persuasiva y visual muy poderosa.

\section{Material y Métodos}

Se analizan los memes de la red social Twitter debido a la influencia social que tiene por su carácter público, capacidad de expansión y porque, según FernándezGómez y Martín-Quevedo (2018 a, p. 1293-94): “es la red social más utilizada a la hora de consumir productos televisivos como segunda pantalla y para acceder y monitorizar la audiencia". Además "los elementos que sorprenden son los más atractivos para viralizar contenidos. Y el humor favorece la viralidad".

Para delimitar el objeto de estudio, conocer cómo Netflix utiliza el meme y lo implementa en sus estrategia creativa en Twitter, se formularon una serie de preguntas:

- P.1. ¿Cuáles son los memes que tienen mayor grado de utilización y engagement en relación con su contenido y formato?

- P-2. ¿Cuáles son los principales formatos y contenidos utilizados para elaborar un meme?

- P-3. ¿Qué objetivo comunicativo se persigue mayoritariamente con su utilización?

\subsection{Objetivos}

El objetivo principal, evaluar si los memes establecen engagement que viralice los contenidos, se dividió en los siguiente objetivos específicos:

- 0.1. Conocer el grado de engagement que tienen los memes con respecto a los demás recursos utilizados por Netflix en su cuenta de Twitter (@NetflixES). 


\section{MONOGRÁFICO}

- 0.2. Averiguar cuáles son los formatos y contenidos de los memes con mayor grado de utilización y engagement en la cuenta de Twitter (@NetflixES).

- 0.3. Identificar a qué objetivos de comunicación responde la utilización del meme.

\subsection{Hipótesis}

Se plantearon las siguientes, basadas en la experiencia de usuario en Twitter:

- H.1. Los tuits que integran un meme tienen mayor engagement que los que no lo tienen.

- H.2. La imagen macro es un formato más utilizado que los clips de video.

- H.3. La promoción de la marca Netflix es el objetivo de comunicación que más se sigue a la hora de utilizar un meme.

\subsection{Metodología}

Se ha utilizado el Análisis de Contenido para llevar a cabo la revisión de los memes insertos en los tuits publicados por la cuenta de Netflix España (@NetflixEs). Dado que aporta datos cuantitativos y/o cualitativos de los que se pueden deducir unas inferencias, en base a unas variables seleccionadas (Krippendorff ,1990, p.11).

\subsection{La muestra}

Se acotó el análisis a los tuits publicados por Netflix en el cuarto trimestre de 2019. Se analizaron todos los tuits originales lanzados por la compañía y los retuits, likes y respuestas que estas publicaciones generaron. La muestra quedó delimitada por un total 307 tuits originales emitidos por la cuenta @NetflixEs. De los que se obtuvieron para el análisis de contenido 112 memes.

Esta muestra permitió inferir la respuesta que la audiencia tiene con respecto a los memes publicados en ese año, es decir, el grado de engagement que tienen con respecto a las demás herramientas comunicativas utilizadas en Twitter, así como 
las características de los memes en cuanto a forma y contenido. En el momento de la investigación, Netflix contaba con un millón de seguidores y aproximadamente 16.400 tuits que ha ido publicando desde que en abril de 2015 abriera su cuenta.

\subsection{Procedimiento}

El análisis se desarrolló en tres fases:

Fase 1. Conocer el grado de engagement que tienen los memes con respecto a los demás recursos utilizados por Netflix España en su cuenta de Twitter (objetivo 1). Para ello se identifican los recursos utilizados en el tuit y el número de interacciones que estos obtuvieron, tomando como referencia la clasificación de Fernández-Gómez y Martín-Quevedo (2018 a, p.1293), siendo:

- Enlaces de redes sociales a otros posts de la plataforma o los tuits que hacen referencia a los de otra persona incrustándolos dentro de su propio contenido.

- Enlace propio a web, que redirigen a los usuarios directamente a visualizar los contenidos.

- Enlace externo, cuyo objetivo es visualizar un contenido alternativo a los de Netflix en Twitter o en su página web.

- Imagen: en la que se incluyen, según Linares (2015), imágenes de: noticias en medios, de cartelería o poster promocional, de una premier o preestreno, todas ellas encaminadas a la autopromoción del contenido.

- Video: en el que se incluyen videos de trailers o teasers, los making of behind the scenes, de noticias en medios o de una premier o preestreno.

- Hashtag: representado por el símbolo de almohadilla (\#) y que funciona según Martínez-Rolán y Piñeiro-Otero (2015) como hipervínculos que aglutinan la conversación social que se genera en Twitter alrededor de un tema concreto. 
- Emoticonos: son imágenes prediseñadas, en su mayoría expresiones faciales, que están insertas en los mensajes electrónicos.

En esta etapa, también se analiza el grado de engagement de aquellos tuits que integran los memes con respecto a los que no y que De Aguilera, Baños y Ramírez (2015) lo definen como la fuerza intrínseca que lleva al usuario a tomar decisiones con respecto a la marca y a guiar su comportamiento. Según la Advertising Research Foundation (2007), citado en González-Bernal (2016, p. 786): “el principal requisito para que se genere el engagement en el consumidor es la apertura emocional. Con relación a esta lógica, el engagement parte de las emociones o los sentimientos experimentados por un usuario, para luego fortalecer los pensamientos $\mathrm{y}$, como consecuencia de ello, realizar un cambio en el comportamiento o en la toma de decisiones".

En relación a la red social Twitter el grado de engagement se puede equiparar al "grado en que el usuario interactúa con la marca" (Del Pino-Silva, 2017, p.47), materializándose en los indicadores de retuits, likes y respuestas. Además, se calculó el coeficiente de interacción que, según Martínez-Rolán y Piñeiro-0tero (2017, p.65); "es aquel que resulta de dividir el número de interacciones totales (retuits, likes y respuestas) entre el número de seguidores del usuario emisor, constituyendo un índice de valor para el análisis de la viralización de contenidos". Es decir, el grado de viralización que aporta este indicador de manera sintética se ha utilizado para medir el nivel engagement que los usuarios de esta red tienen con los contenidos publicados.

En el caso de la cuenta de @NetflixEs acumulaba un total de 1.050.312 seguidores en el momento en el que se registraron los datos. Posteriormente, se pasó a hacer un recuento del número de veces que cada tuit alberga dichos recursos y se sumaron todos los índices de interacción generados por cada cada uno de ellos (interacciones totales por cada recurso). Estos dos valores (interacciones totales por cada recurso y número de veces que se repite cada recurso) se dividieron entre sí para hallar el índice de interacción que tiene cada recurso de media por cada tuit.

Fase 2. Averiguar cuáles son los formatos y contenidos de los memes con mayor grado de utilización y engagement en la cuenta de Twitter (@NetflixES) (objetivo 
2). Para ello se lleva a cabo un análisis de contenido de las siguientes variables (Martínez-Rolán y Piñeiro-0tero, 2015, p.150):

1. La manifestación: "es la materialización del meme en sí misma, es decir su fenómeno externo". En él se analizaron los siguientes formatos en los que se presentan los memes:

- Texto visual: Es un tipo de imagen a la que podemos adjudicar más de un significado, por lo que podemos configurarla de diferentes maneras. La clave para ello estará en el texto, que es el elemento que lo enmarca. Cada persona interpreta una imagen de acuerdo a su esquema metal que es con el que decodifica todos los componentes que la integran.

- Imagen macro: en este formato, las imágenes no sirven para ilustrar el texto que les acompaña y reducirlo, sino que "la amplifica y abre su significado por la vía de la paradoja" (Ruiz-Martínez, 2018, p.1014). Es decir, la imagen macro dota al texto de esquemas culturales y de todo un imaginario. Por norma general todas ellas suelen estar acompañadas de un texto superpuesto o en un marco negro.

- Collage de fotos: Se intercalan fotos que se refieren a diferentes contenidos de la plataforma formado con ellas un único mensaje.

- Gráfico. En forma esquematizada a través de figuras, símbolos o emoticonos se transmite un mensaje concreto.

- Tabla. Se elabora un esquema en el que se aporta información de los diferentes contenidos.

- Captura de pantalla. Se utilizan planos concretos de las series, película o documentales.

Además de todos estos formatos se añadió una categoría más al análisis que podía ser aglutinadora de diferentes memes y completar de manera acertada el estudio:

- Clips de video en la que se exponen fragmentos de los contenidos publicados por la marca. 


\section{MONOGRÁFICO}

2. Comportamiento: Las diferentes acciones que los usuarios realizan para perpetuar la trasmisión del meme, es decir, compartirlo como tal o realizar diferentes tipos de retoques a la imagen. Se configuraron dos tipos de variables.

- Retoque de la imagen: es decir, si se había codificado sus aspectos formales con algún tipo de programa de edición.

- Integración de texto en la imagen: aumentando sus posibilidades de reconfiguración con respecto al contenido original de la imagen referida. Para su codificación se distinguieron la siguientes subvariables:

- Texto original

- Parafrasea meme

- Sin texto

- Idéntico al original

3. Ideal, que es el concepto que subyace al meme (Ruiz-Martínez, 2018, p.1001). Para este aspecto se configuraron dos variables:

- Objetivo comunicativo: seguido por la cuenta de Netflix.

- Temática: para su consecución se llevó a cabo un etiquetado de los memes en base a sus aspectos formales, además de tener en cuenta elementos como los hashtags y otros elementos textuales para configurar su significado.

Fase 3. Identificar a qué objetivos de comunicación responde la utilización del meme (objetivo 3.). Para ello se cogieron los datos recabados en el apartado ideal de la fase anterior y se siguió el modelo planteado por los autores FernándezGómez y Martín-Quevedo (2018 b) en los que catalogan los tuits publicados por la cuenta de Netflix según los objetivos que persiguen. Todos ellos son descritos por Del Pino-Silva (2017) quien los condensa en seis puntos diferentes para encuadrarlos en las estrategias de comunicación que se aplican a la promoción de productos audiovisuales:

Promoción de la marca Netflix: en los que incluye los tuits con los siguientes objetivos: 
El fenómeno del meme en la estrategia creativa de Nefflix España en Twitter | 326

MONOGRÁFICO

- Dar información acerca de noticias o los servicios que otorgue la plataforma como las fechas de las premieres que están por llegar o anunciar nuevos eventos.

- Saludar o apelar a los seguidores con mensajes informales y con un tono humorístico para conectar mejor con ellos.

- Lanzar mensajes cuya promoción sea directamente la marca Netflix con mensajes que contengan por ejemplo el hashtag \#SoloEnNetflix o que haga referencia a los maratones de series.

Promoción del contenido audiovisual del catálogo: que contienen información o un mensaje encaminado a la promoción de sus series, películas y documentales.

- Establecer una conversación con los usuarios: invitándoles a participar en diferentes debates, que respondan alguna pregunta, o respondiendo tuits lanzados por los propios seguidores.

Compartir contenido alternativo: mensajes que no atañen a la marca, siendo algo externo y de actualidad.

- Proponer concursos, juegos o quiz a los seguidores: donde la marca les invita a participar con el objetivo de conseguir más seguidores y aumentar su notoriedad.

- Invitación a la participación en encuestas: cuyo objetivo es conocer la opinión acerca de un tema planteado a través de la herramienta de encuestas de Twitter.

\section{Resultados:}

\subsection{Análisis de la Fase 1}

Se realizó la revisión de los 307 tuits originales emitidos por la cuenta de @NetflixEs que arrojó luz sobre la utilización de los memes por parte de la plataforma y su interacción con la audiencia. A continuación, se examinan los datos obtenidos del análisis de los recursos. 
MONOGRÁFICO

\begin{tabular}{|l|c|c|c|c|c|}
\hline & \multicolumn{2}{|c|}{ GRADO DE UTILIZACIÓN } & \multicolumn{2}{c|}{ GRADO DE ENGAGEMENT } \\
\hline Recurso & $\begin{array}{c}\text { No de veces } \\
\text { utilizado el } \\
\text { recurso en } \\
\text { cada tuit }\end{array}$ & $\begin{array}{c}\text { Porcentaje } \\
\text { de } \\
\text { utilización }\end{array}$ & $\begin{array}{c}\text { Interacciones } \\
\text { totales } \\
\text { Media de } \\
\text { interacciones } \\
\text { por recurso }\end{array}$ & $\begin{array}{c}\text { Coeficiente de } \\
\text { interacción }\end{array}$ \\
\hline $\begin{array}{l}\text { Enlace en } \\
\text { redes sociales }\end{array}$ & 15 & $3 \%$ & 60533 & 4036 & 0,0038 \\
\hline Emoticono & 22 & $4 \%$ & 92903 & 4223 & 0,0040 \\
\hline Meme & 112 & $24 \%$ & 260074 & 2322 & 0,0022 \\
\hline Texto & 294 & $16 \%$ & 608560 & 2070 & 0,0020 \\
\hline Hashtag & 74 & $16 \%$ & 140535 & 1899 & 0,0018 \\
\hline Imagen & 154 & $33 \%$ & 261715 & 1699 & 0,0016 \\
\hline Video & 93 & $20 \%$ & 133007 & 1430 & 0,0014 \\
\hline
\end{tabular}

Tabla 1: Grado de utilización y engagement de cada recurso utilizado por Netflix España en Twitter. (Autores, 2020). Fuente: Elaboración propia.

Después de la revisión de los 307 tuits, en la tabla 1 se constata que el recurso más utilizado con un 33\% de los casos es la imagen, repetida 154 veces y acompañada a su vez de otros recursos como son los memes, los cuales ocuparon el segundo lugar con un $24 \%$, repetidos 112 veces, o los hashtag con un $16 \%$ y repetidos 74 veces.

Sin embargo, si nos referimos al nivel de engagement que los recursos han generado en los seguidores de Netflix, podemos ver que a la cabeza están aquellos tuits que albergan un emoticono, cuyo coeficiente de interacción es del 0'0040. Esto significa que por cada publicación que tenga un emoticono se registraron 4223 interacciones de media. Por detrás de este, se encontraron otros como el enlace en redes sociales cuyo coeficiente es 0,0038 , con un total de 4036 interacciones medias por cada post $\mathrm{y}$, en tercer lugar, el meme con un coeficiente de interacción del 0,0022 y un total de 2322 interacciones de media. 
El fenómeno del meme en la estrategia creativa de Netflix España en Twitter | 328

MONOGRÁFICO

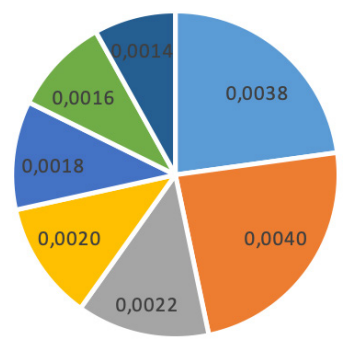

" Enlace en redes sociales " Emoticono " Meme " Texto " Hashtag " Imagen " Video

Gráfico 2: Coeficiente de interacción por cada recurso. Fuente: elaboración propia.

\subsection{Análisis de la Fase 2}

Se registraron un total de 112 memes, convirtiéndose en el segundo recurso más utilizado por la plataforma de streaming. Para hacer un análisis del grado de utilización y engagement de manera detallada, el estudio se basó en los tres aspectos diferenciales ya señalados: manifestación, comportamiento e ideal del meme. A su vez, cada uno albergó diferentes subvariables codificadas anteriormente. Los datos recabados se sintetizan en la tabla 2 cuyo objetivo es el análisis de la manifestación de los 112 memes analizados.

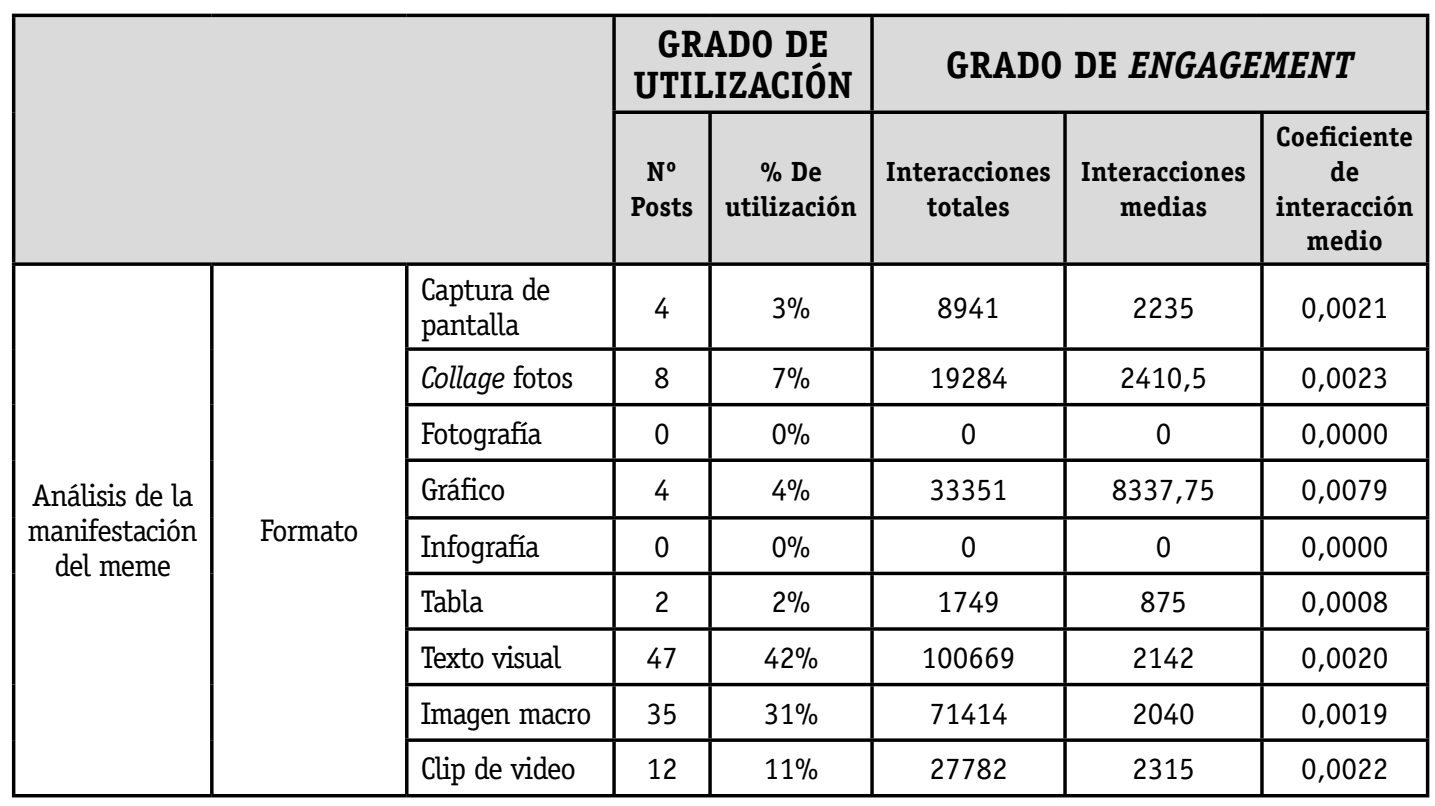




\section{MONOGRÁFICO}

\begin{tabular}{|c|c|c|c|c|c|c|c|}
\hline & \multicolumn{2}{|c|}{$\begin{array}{c}\text { GRADO DE } \\
\text { UTILIZACIÓN }\end{array}$} & \multicolumn{3}{|c|}{ GRADO DE ENGAGEMENT } \\
\hline & & & $\begin{array}{l}\mathrm{N}^{0} \\
\text { Posts }\end{array}$ & $\begin{array}{c}\text { \% De } \\
\text { utilización }\end{array}$ & $\begin{array}{c}\text { Interacciones } \\
\text { totales }\end{array}$ & $\begin{array}{c}\text { Interacciones } \\
\text { medias }\end{array}$ & $\begin{array}{c}\text { Coeficiente } \\
\text { de } \\
\text { interacción } \\
\text { medio }\end{array}$ \\
\hline \multirow{6}{*}{$\begin{array}{l}\text { Análisis del } \\
\text { comporta- } \\
\text { miento del } \\
\text { Meme }\end{array}$} & \multirow{2}{*}{$\begin{array}{c}\text { Retoque en la } \\
\text { imagen }\end{array}$} & $\mathrm{Si}$ & 15 & $13 \%$ & 13097 & 873 & 0,0008 \\
\hline & & No & 97 & $87 \%$ & 249112 & 2568 & 0,0024 \\
\hline & \multirow{4}{*}{$\begin{array}{l}\text { Integración } \\
\text { de texto en } \\
\text { la imagen }\end{array}$} & Idéntico & 0 & 0 & 0 & 0 & 0,0000 \\
\hline & & Original & 96 & $86 \%$ & 230169 & 2398 & 0,0023 \\
\hline & & $\begin{array}{l}\text { Parafrasea } \\
\text { meme }\end{array}$ & 16 & $14 \%$ & 32040 & 2003 & 0,0019 \\
\hline & & Sin texto & 0 & & 0 & 0 & 0,0000 \\
\hline \multirow{8}{*}{$\begin{array}{l}\text { Análisis del } \\
\text { ideal del } \\
\text { meme }\end{array}$} & \multirow{5}{*}{$\begin{array}{c}\text { Objetivo } \\
\text { comunicativo }\end{array}$} & $\begin{array}{l}\text { Promoción } \\
\text { de la } \\
\text { marca Netflix }\end{array}$ & 64 & $57 \%$ & 157856 & 2467 & 0,0023 \\
\hline & & $\begin{array}{l}\text { Promoción } \\
\text { del contenido } \\
\text { audiovisual } \\
\text { del catálogo } \\
\end{array}$ & 39 & $35 \%$ & 67787 & 1738 & 0,0017 \\
\hline & & $\begin{array}{l}\text { Establecer una } \\
\text { conversación } \\
\text { con los } \\
\text { usuarios } \\
\end{array}$ & 9 & $8 \%$ & 22649 & 2517 & 0,0024 \\
\hline & & $\begin{array}{l}\text { Compartir } \\
\text { contenido } \\
\text { alternativo } \\
\end{array}$ & 0 & $0 \%$ & 0 & 0 & 0,0000 \\
\hline & & $\begin{array}{l}\text { Proponer con- } \\
\text { cursos, juegos } \\
\text { o quiz a los } \\
\text { seguidores: }\end{array}$ & 0 & $0 \%$ & 0 & 0 & 0,0000 \\
\hline & \multirow{3}{*}{$\begin{array}{c}\text { Temática del } \\
\text { meme }\end{array}$} & $\begin{array}{l}\text { Conducta } \\
\text { opuesta a lo } \\
\text { esperado }\end{array}$ & 10 & $9 \%$ & 24018 & 2402 & 0,0023 \\
\hline & & $\begin{array}{l}\text { Enmarcar una } \\
\text { emocion/ } \\
\text { conducta/ } \\
\text { situación } \\
\end{array}$ & 86 & $77 \%$ & 24018 & 2450 & 0,0023 \\
\hline & & $\begin{array}{l}\text { Referencia a } \\
\text { elementos de } \\
\text { las series }\end{array}$ & 16 & $14 \%$ & 27520 & 1720 & 0,0016 \\
\hline
\end{tabular}

Tabla 2: Análisis del grado de utilización y engagement de los memes de Netflix España en Twitter (Díaz-Molina y Arroyo-Almaraz, I. (2020). Fuente: Elaboración propia. 
En referencia a la variable formatos, se observa que el más utilizado fue el texto visual con un $42 \%$ de total ( 47 publicaciones). Su mayor presencia indica una apropiación por parte de la plataforma de unas composiciones de imagen y texto muy estereotipadas. Aquí el texto es el que termina de dar sentido a la imagen y lo encuadra. El segundo formato más utilizado fue la imagen macro, presente un $31 \%$ de los memes (35 publicaciones) y, el tercero, el clip de video con el 11\% (12 publicaciones). Todos los formatos se caracterizaron por recoger imágenes 0 fragmentos de video de las series, películas y documentales de la plataforma. Además, fueron publicados con mensajes que emulan las dinámicas comunicativas que su audiencia adopta en esta plataforma.

Por otro lado, el formato que consiguió un mayor grado de engagement fue el gráfico con un coeficiente de interacción del 0,0079 (8837,75 interacciones de media por cada post) seguido por el collage de fotos con un 0,0023 de coeficiente (2410,5 interacciones de media) y el clip de video con un 0,0022 de coeficiente (2315 interacciones de media). La simbología utilizada por los gráficos para expresar una idea concreta y conectar emocionalmente con la audiencia se caracterizó por su originalidad y provocó una mayor interacción de los seguidores con el contenido.

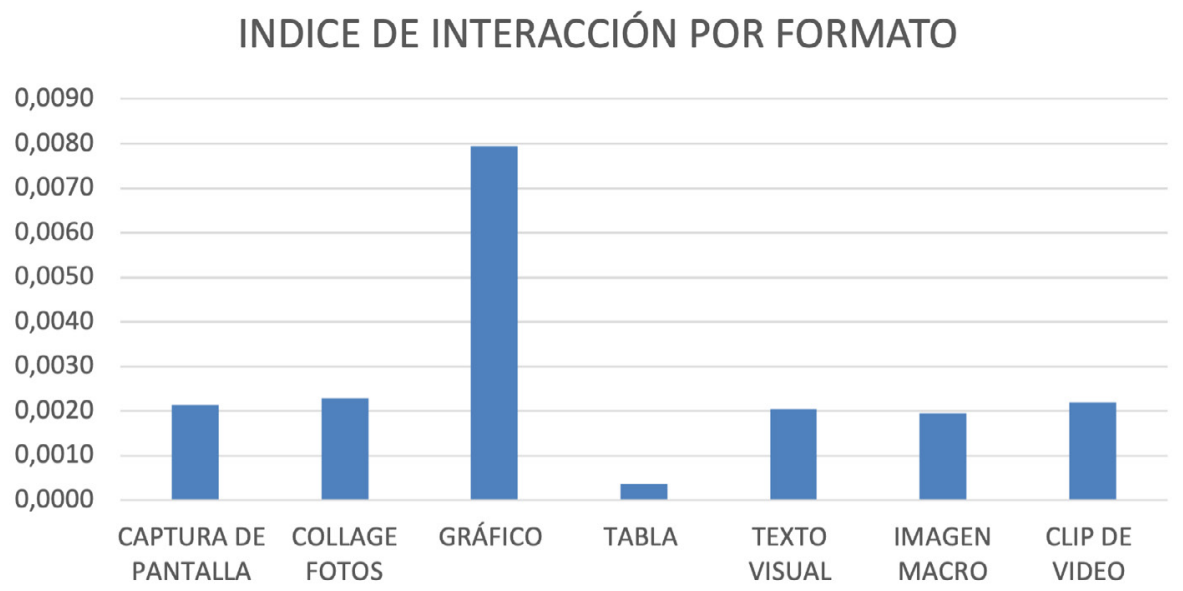

Gráfico 3: Coeficiente de interacción por formato. Fuente: elaboración propia. 


\section{MONOGRÁFICO}

En referencia al grado de utilización de las técnicas de retoque podemos afirmar que, en una gran mayoría de publicaciones, el retoque con programas de edición no fue efectivo, siendo este del 87\% (97 publicaciones) frente al 13\% (15 publicaciones)donde sí hubo alguna modificación de los aspectos formales, con programas como Photoshop. Esto constata la intencionalidad que tiene Netflix a la hora de mostrar un contenido original, seleccionando imágenes de manera estratégica y siendo fácilmente identificables.

Enfocando el grado de engagement, las imágenes con algún tipo de retoque adquirieron un coeficiente de interacción del 0,0008 (873 interacciones de media), frente a un 0,0024 (2568 interacciones de media) en las que no tuvieron algún retoque en la imagen. Es decir, los usuarios interactuaron más con aquellas imágenes que no tenían ningún tipo de retoque.

\section{Integración de texto en la imagen}

Las subvariables que se establecieron fueron: texto original, parafrasea meme, idéntico al original y sin texto. Sin embargo, solo se utilizaron dos de estas categorías: texto original y parafrasea meme.

Por un lado, el grado de utilización del texto original fue del $86 \%$ (96 publicaciones) frente al 14\% (16 publicaciones) que simplemente parafraseaban memes no originales con estructuras discursivas, como por ejemplo "-Yo... +También yo..." 0 “-Al principio de la década... + Al final de la década.

Por otro lado, el grado de engagement se relacionó directamente con el grado de utilización, ya que los memes que poseían un texto original alcanzaron un coeficiente de interacción más alto que los que lo parafraseaban. Las interacciones que obtuvo un meme con un texto original fueron de 2398 frente a las 2003 que alcanzaron aquellos que simplemente se adaptaron a una estructura discursiva ya prediseñada.

Las imágenes que acompañaban al texto se convirtieron, a su vez, en el elemento central del meme. Sin embargo, cuando ese texto parafraseaba otro meme 
se convertía en un elemento que lo anclaba al contenido gráfico. Esta unión hace referencia, como decía Shifman (2014), a las constelaciones de memes que los preceden y los hacen reconocibles para todos los usuarios. Bajo esta visión, los memes se convertían en componentes no delimitados que van mutando a través de pequeños cambios en su estructura.

\subsection{Análisis de la Fase 3}

Se analizaron las dos variables del objetivo comunicativo del meme: la finalidad que tiene Netflix y el asunto tratado.

\section{La finalidad que tiene Netflix}

La promoción de la marca Netflix fue el objetivo más seguido en los diferentes memes con un 57\% (64 publicaciones). Se caracterizaron por tener un mensaje en clave humorístico o informal haciendo referencia a la marca o aspectos que identifican de manera emocional a sus seguidores. Los insights de la audiencia y el lenguaje utilizado se convirtieron en el elemento central para llamar su atención.

Seguido de la promoción del contenido audiovisual del catálogo con el 35\% (39 publicaciones) que se realizó a través de diferentes recursos: los hashtags, el texto o la propia imagen.

Por último, la conversación con el usuario con el 8\% (9 publicaciones).

También debemos destacar la inexistencia de memes que estuvieran encaminados a proponer concursos o juegos, así como los que tuvieran el objetivo de invitar a la audiencia a participar en encuestas y promocionar un contenido alternativo. 


\section{MONOGRÁFICO}

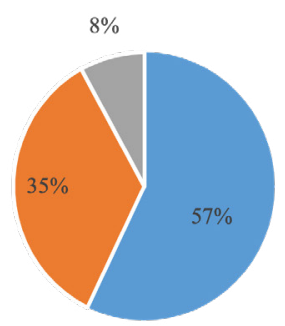

Promoción de la marca Netflix

Promoción del contenido audiovisual del catálogo

Establecer una conversación con los usuarios

Gráfico 4: Grado de utilización de los objetivos comunicativos. Fuente: elaboración propia.

En cuanto al grado de engagement se invirtieron los valores con respecto a grado de utilidad, ya que los objetivos comunicativos menos usados fueron los que más coeficiente de interacción obtuvieron. Establecer una conversación con el usuario generó un coeficiente de interacción del 0,0024 (2517 interacciones de media por cada tuit). Esto se debió a que los posts inician un debate o apelan directamente a la opinión de la audiencia. La fuerza que ejerció la plataforma para movilizar a la audiencia se tradujo en un mayor número de interacciones.

\section{El asunto tratado}

En primer lugar, en un $77 \%$ de los casos, los memes se utilizaron para enmarcar una emoción, conducta o situación (86 publicaciones). Los memes fueron diseñados principalmente para apelar de manera directa a los sentimientos o conductas que tiene el público, y con los que ellos se sientan identificados. En palabras de RuizMartinez (2018, p. 1012):“se produce una cualidad semiótica fundamental para la comprensión del meme: la imagen implica, una cara (humana o animal), especialmente expresiva, que sugiere de forma manifiesta (y estereotipada) algún tipo de emoción (perplejidad, asco, hilaridad, horror), casi siempre ridícula o risible".

En segundo lugar, se posicionaron aquellos memes que hacen referencia a elementos de las series con un 14\% (16 publicaciones). Aquí el meme no hizo referen- 
cia al espectador, sino que tomó como figura central elementos que tuvieran que ver con los contenidos de Netflix y los enmarcaron en una estructura discursiva que imita a un meme.

En tercer lugar, se posicionaron aquellos que hicieron referencia a una conducta opuesta a lo esperado con un 9\% (10 publicaciones). Esta temática se hace muy fuerte debido a la figura de la paradoja que es enmarcada por una imagen llena de simbolismo. La imagen alberga todo un universo icónico que complementa su significado y crea un efecto humorístico.

En cuanto al nivel de engagement se pudo apreciar que los memes con el mayor coeficiente de interacción fueron aquellos que enmarcaron una emoción, conducta o situación con un 0,0023 (2450 interacciones de media), como se puede ver en la Tabla 2, muy seguida aquellos que reflejaron una conducta opuesta a lo esperado con un 0,0022 (2402 interacciones de media). Por último, se encontraron aquellos memes que hacen referencia a elementos de la series con un coeficiente de 0,0016 (1720 interacciones de media). Esto significa que los memes que apelan directamente a emociones o conductas son más susceptibles de tener un índice de interacciones mayor que aquellos que simplemente se refieren a elementos propios de los contenidos creados por Netflix.

\section{Refencia a elementos de las series}

Enmarcar una emoción/conducta/situación

Conducta opuesta a lo esperado

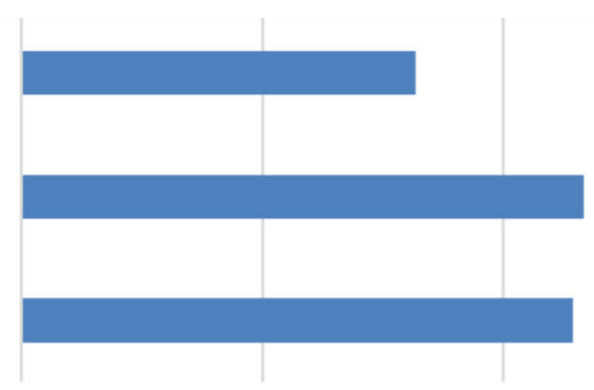
0,00000
0,00100
0,00200
0,00300

Gráfico 5: Coeficiente de interacción de la temática de los memes. Fuente: elaboración propia. 


\section{Discusión}

Como conclusión general se constata el empleo estratégico de numerosas imágenes y videos para la comunicación de diferentes ideas, cuya finalidad es llamar la atención de la audiencia. Los memes presentan una manifestación más informal que otros contenidos promocionales de Internet. En ellos se combina la promoción de contenido con un enlace emocional con los consumidores. Esta unión se vale de un universo icónico que pueden albergar las imágenes por los personajes que aparecen, las situaciones en las que se encuentran o los sentimientos que expresan.

Teniendo en cuenta el objetivo general de la investigación por el que se analizó el papel del meme en la estrategia creativa de Netflix, podemos afirmar que esta herramienta tiene un uso destacado en su actividad comunicativa a través redes sociales, pero complementada con otro tipo de contenido con un carácter más tradicional como son los tráilers o los posters promocionales.

En cuanto a las hipótesis de partida planteadas:

No se confirma la hipótesis 1 debido a que los tuits que integraban un emoticono (4223 interacciones de media) o aquellos que tenían un tuit incrustado (4036 interacciones de media) a modo de enlace interno tenían más interacciones que aquellos que contenían un meme (2322 interacciones de media). Esto se debe a que los emoticonos se utilizan tanto en mensajes informativos como en mensajes más informales. Además, los tuits incrustados son una herramienta que Netflix utiliza para referirse a personajes famosos y que encajan dentro de los referentes que tiene su público objetivo.

Se confirma la hipótesis 2. En un 31\% de los memes se utilizó la imagen macro frente al 11\% donde se utilizó el clip de video. La imagen macro tiene más posibilidades meméticas que el clip de video, ya que en ellas se utilizan imágenes con personajes de referencia o situaciones que dotan de significado al texto que las acompaña, siempre de carácter paradójico o incongruente. Además, la estructura en sí da pie a diferentes configuraciones en base a las necesidades del emisor. 
Se confirma la hipótesis 3, ya que podemos inferir que el contenido audiovisual se utiliza en un $57 \%$ de las publicaciones realizadas. Esto hace referencia a una de las cualidades más importantes de los memes, la de configurarse como mensajes informales y estructurados en clave de humor, utilizando los insights de su público objetivo y su lenguaje para relacionarse con ellos.

Comparando nuestros resultados con los de investigaciones precedentes abrimos una discusión sobre la importancia del vínculo emocional y el comportamiento de los memes en diferentes redes sociales.

Se refuerzan los resultados ya encontrados por Giraldo-Cuéllar y 0spina-Echeverri (2020), para el caso particular de la serie española La Casa de Papel, donde se confirma que los memes son beneficiosos para la marca porque mejoran el engagement con sus usuarios y crean un vínculo emocional muy poderoso, gracias a que sus contenido están estrictamente ligados a las intenciones de comunicación de la marca en relación a la producción, divulgación y consumo de la serie.

Nuestros resultados también ratifican los encontrados por Doñate-Ventura (2020) para el caso particular de la serie Paquita Salas cuyo éxito se basa igualmente en los vínculos emocionales creados a través del humor y la nostalgia.

Igualmente esta investigación corrobora algunos de los datos de la investigación de Martín-Quevedo, Fernández-Gómez y Segado-Boj (2019) que concluye, para Instagram, que el humor y el tono positivo estaban relacionados con un mayor engagement de los usuarios.

Futuras investigaciones deberían ampliar el análisis a las diferentes redes sociales que utiliza Netflix en la estrategia creativa que realiza en España y hacer un estudio comparativo entre sus diferentes usos dentro de la estrategia creativas para estudiar el comportamiento de los memes en cada una de ellas. Así como ampliar la muestra, teniendo en cuenta que el ritmo de publicaciones de Netflix en las diferentes redes sociales se incrementa cada año. 


\section{Referencias}

Chans, F. (21 de diciembre de 2018). Meme marketing: la apuesta viral que es tendencia entre las marcas, en http://bit.ly/3gTcBlR

Davidson, P. (2012). The Language of Internet Memes. En M. Mandiberg. (Ed.), The Social Media Reader (pp.120-134). New York: Centro de prensa de la Universidad de New York. Dawkins, R.(1976). El Gen Egoísta. Barcelona, España: Salvat Editores, S.A.

Dawkins, R. (2004). A devil's chaplain: Reflections on hope, lies, science, and love. Houghton Boston-New York: Mifflin Harcourt Company.

DeAguilera,J.,Baños-González, M.y Ramírez-Perdiguero,J.(2015). Branded entertainment: Los contenidos de entretenimiento como herramienta de comunicación de marketing. Un estudio de su situación actual en España. Revista Latina de Comunicación Social, 70, pp. 519-538. DOI: http://dx.doi.org/10.4185/RLCS-2015-1057

Del Pino-Silva, J. (2017). Estrategias de Comunicación Aplicadas a La Promoción de Productos Audiovisuales. El Caso de Netflix En Twitter (tesis de grado). Sevilla: Universidad de Sevilla.

Díaz-Molina y Arroyo-Almaraz, I. (2020). Datos El fenómeno del meme en la estrategia creativa de Netflix España. Open Science Framework, en https://osf.io/82rzu/.

Doñate-Ventura, J. (2020). Paquita Salas en Netflix.Un análisis de la cultura pop española. En: Comunicación y diversidad. Selección de comunicaciones del VII Congreso Internacional de la Asociación Española de Investigación de la Comunicación (AE-IC), 28-30 de octubre, pp. 247-254. Valencia: El Profesional de la Información SL.

Fernández-Gómez, E.; Martín-Quevedo, J. (2018 a). La Estrategia de Engagement de Netflix España en Twitter. El profesional de la información, 6(27), pp.12921302. DOI: http://dx.doi.org/10.3145/epi.2018.nov.12

Fernández-Gómez, E.; Martín-Quevedo, J. (2018 b). Connecting with audiences in new markets: Netflix Twitter strategy in Spain. Journal of Media Business Studies, 2(15), pp.127-146. DOI: http://dx.doi.org/10.1080/16522354.2018.1481711

Giraldo Cuéllar, J.S.; Ospina Echeverri, J.P. (2020) Análisis del Uso táctico del Meme en la Estrategia Publicitaria de Netflix para la Tercera Temporada de la Serie La Casa de Papel, en https://red.uao.edu.co/bitstream/10614/12371/6/T09221.pdf

González-Bernal, M. I. (2016). Hacia la comprensión del engagement de las audiencias de televisión, modelo conceptual multidimensional desde la comunicación. Palabra Clave 19(3), 769-809. D0I: http://dx.doi.org/10.5294/pacla.2016.19.3.5 
Groupe $\mu$ (1993). Tratado del signo visual. Madrid: Cátedra.

Krippendorff, K. (1990). Metodología de análisis de contenido. Teoría y práctica. Barcelona: Paidós.

Herbera, J.; Linares, R.; Neira, E. (Coord) (2015). Marketing cinematográfico. Cómo promocionar una película en el entorno digital. Barcelona: Editorial UOC.

Lankshear, C. y Knobel M. (2007) Researching New Literacies: Web 2.0 practices and insider perspectives. E-Learning 3(4), pp.224-240. DOI: https://doi. org/10.2304/elea.2007.4.3.224

Martín-Quevedo, J.; Fernández-Góme y E.;Segado-Boj, F (2019) How to Engage with Younger Users on Instagram: A Comparative Analysis of HBO and Netflix in the Spanish and US Markets, International Journal on Media Management, 21:2, 67-87. D0I: http://dx.doi.org/10.1080/14241277.2019.1585355

Martínez-Rolán, L. X.; Piñeiro-Otero, T. (2015). Los memes en el discurso de los partidos políticos en Twitter: análisis del Debate sobre el Estado de la Nación de 2015. Communication \& Society, 29(1), pp.145-160. D0I: http://dx.doi.org $\angle 10.15581 / 003.29 .1 . s p .145-160$

Martínez-Rolán, L. X.; Piñeiro-Otero, T.(2017). El uso de los memes en la conversación política 2.0. Una aproximación a una movilización efímera. Revista Prisma Social, 18, pp.55-84. En http://bit.ly/2KdnEKt

Milner, R. M. (2012). The World Made Meme: Discourse and Identity in Participatory Media. Kansas: Faculty of the University of Kansas

Puro Marketing (2017, 10 de mayo) Meme marketing: Cuando las marcas y empresas intentan hablar en viral, en http://bit.ly/3gQNAHI

Pérez, G.; Aguilar, A. y Guillermo, M.E. (2014). El meme en Internet. Usos sociales, reinterpretación y significados, a partir de Harlem Shake. CDMX, México: Universidad Autónoma Metropolitana.

Ruiz-Martinez, J. M.(2018). Una aproximación retórica a los memes de Internet. Revista Signa, 27, pp.995-1021. D0I: https://doi.org/10.5944/signa.vol27.2018.21856 Shifman, L. (2014) Memes in Digital Culture (edit.). Cambridge, MA: MIT Press Torres, A. (2015, 30 de julio). La génesis del meme, en http://bit.ly/2K91xF7

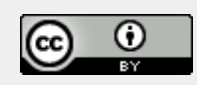

Este obra está bajo una licencia de Creative Commons Reconocimiento 4.0 Internacional. 